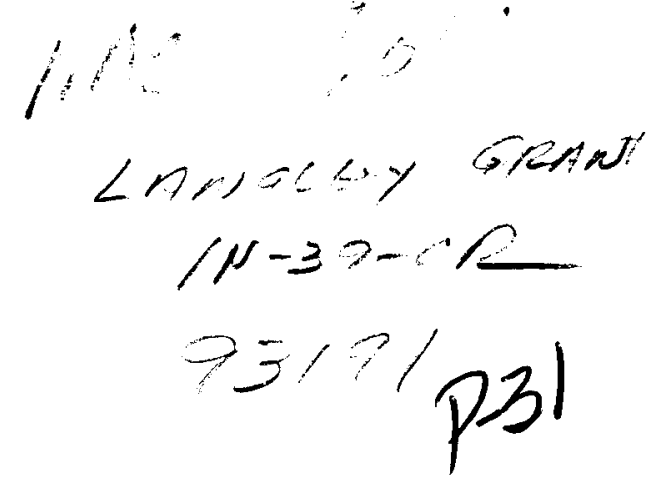

A COMPRESSIVE FAILURE MODEL FOR ANISOTROPIC PLATES WITH A CUTOUT

UNDER COMPRESSIVE AND SHEAR LOADS

\author{
Zafer Gürdal \\ Assistant Professor \\ Department of Engineering Science and Mechanics \\ Virginia Polytechnic Institute and State University \\ Blacksburg, VA 24061 \\ Phone: (703) 961-5905 \\ Raphae1 T. Haftka \\ Professor \\ Department of Aerospace and Ocean Engineering \\ Virginia Polytechnic Institute and State University \\ Blacksburg, VA 24061 \\ Phone: (703) 961-4860
}

Final Technical Report

Prepared for NASA Langley Research Center

Under the Grant NAG-1-601

(NASA-CE-181264) A CCERBESSIVE FAILURE

DCDEL FCR ANISOTECEIC FLATES WITH A CUTOUT

DNLER CCHERESSI VE AND SHEAE ICALS Final

Technical Refcrt (Virginia fclytechnic

Irst. and state uriv.l 31 f avail: NTIS

N87 -28044

$-1-$ 
Introduction:

Compressive failure of plates with a cutout can be modeled by considering either the strength failure or the loss of stability of the load-carrying fibers. Strength failure predictions based on point-stress and average-stress criteria, originally developed for tensile loadings, have been used [1-3] for compressive loadings. In the application of the point-stress criterion, for example, compressive failure of the fibers at a pre-determined distance from the hole boundary under the action of longitudinal stress along the fiber is assumed. Despite its tempting simplicity, the point-stress criterion does not provide insight into the local material behavior and does not relate the local behavior to the failure process. Failure of composite materials is generally complex and micromechanically governed. It is important that the physical characteristics of the actual failure process be reflected by an appropriate model. A microbuckling failure criterion [4-5] is a step in this direction. It can be applied to the principal load-carrying fibers at a point in a similar fashion as the point-stress criterion. Microbuckling has been shown to be a critical failure mode for composites with a highly flexible matrix material. For practical composites with a high modulus resin, such as graphite/epoxy, microbuckling occurs at load values much higher than observed in experiments [5]. Moreover, similar to the recent applications of the point-stress failure criterion [2-3], microbuckling criterion assumes the failure to be the result of unidirectional stresses along the fiber direction. It is suspected that shearing stresses, either induced by the presence of a discontinuity or resulting from externally applied loads, may affect the compressive failure.

Experimentally observed shear crippling failure mode [2], Fig 1, for plates with a hole is believed to be [6] the result of kinking failure of the principal 
load-carrying fibers. Fiber kinking is characterized by a band of buckled and fractured fibers, Fig 2, in a laminate at a point near a notch, cutout, or a defect under the action of both shearing and compressive deformations [7-10]. Therefore, a change in the relative magnitudes of the shearing and compressive stresses for different layups may affect the failure load. The effect of shearing stresses may be particularly important for anisotropic laminates or for plates under combined compressive and shearing loads.

The present work is an investigation of a failure model for orthotropic and anisotropic plates with a hole under combined in-plane loadings. A model previously developed for fiber kinking failure of load-carrying plies near a crack [11] under combined local compressive and shear loadings is applied to plates with holes. A different version of the model, which is expected to be suitable for cases which the shear failure is dominant, is also developed. In addition to the externally applied compressive load, in-plane shear loading is also considered. To demonstrate the models, failure predictions are first compared with available experimental results for quasi-isotropic and orthotropic laminates under axial loading. The applied loading is then extended to a combined axial and shear loading. Predictions are also made for anisotropic laminate configurations, obtained by rotating the principal axis of orthotropy with respect to the load direction. 


\section{Failure Models:}

The failure models presented in this paper include the effects of local compressive and shearing stresses near a cutout on the failure of load-carrying fibers. These stresses may be the result of externally applied normal loads along the axis of the plate [11], or as a result of combined axial and shear loads. The models modify Rosen's microbuckling model [4] to include the shearing stresses. Individual fibers are modeled as beams on elastic foundation. The cross section of the fiber beam is rectangular with a thickness equal to the fiber thickness $h$ and a unit depth. The thickness of the foundation is equal to the distance between the fibers, 2c, Fig 3-a. Following Rosen[4], shearing deformation of the fibers and the extensional deformation of the matrix are neglected. Two assumptions concerning boundary conditions are tried. First the fiber ends are assumed to remain straight and one end left free to deflect sideways under the action of the side force resulting from the shearing stresses, Fig 3-b. Second, a fiber model with simply supported end conditions is considered, Fig. 3-c. The two assumptions for the boundary conditions have led to two different failure models. Following is the derivation and discussion of the two models.

An energy approach is used for the formulation of the equilibrium equation and boundary conditions for the fiber. Taking the first variation of the total energy of the system, the equilibrium equation of the system can be obtained as

$$
\left(E_{f} I_{f} v^{\prime \prime}\right)^{\prime \prime}+\left[P_{f}-2 c G_{m}\left(1+\frac{h}{2 c}\right)^{2}\right] v^{\prime \prime}=0
$$

and general boundary conditions at $x=0$ and $x=\ell$ as,

$$
\begin{array}{lll}
I \text { - either } & v=0 \text { or } & -\left(E_{f} I_{f} v^{\prime \prime}\right)+\left[2 c G_{m}\left(1+\frac{h}{2 c}\right)^{2}-P_{f}\right] v^{\prime}-q_{f}=0 \\
I I-\text { either } & v^{\prime}=0 \text { or } & E_{f} I_{f} v^{\prime \prime}=0
\end{array}
$$


the fiber stress for the principal load-carrying lamina. The value of the maximum stress that can be carried by a fiber is not well established in the literature, and is assumed here to be $2400 \mathrm{MPa}$. The value of the fiber length assumed for the model is $\ell=0.05 \mathrm{~mm}$. This is a representative value for the length of broken fiber fragments observed in reference 10 .

Simply Supported Ends: At $\mathrm{x}=0$ the $\mathrm{v}=0$ and the force boundary condition of group II apply. For $\mathrm{x}=\ell$, the force conditions of the both groups I and II apply. With the simply supported end conditions the fiber microbuckling load is obtained to be independent to the fiber length. In fact, the critical fiber load is exactly same as the one used by Rosen. But, as opposed to the Rosen's model, before the microbuckling load is achieved the fiber deforms sideways (linearly in $\mathrm{x}$ direction), Fig. 3-c, resulting in a constant shearing stress along the fiber without bending it. The magnitude of the shearing stress is given by

$$
\tau_{\mathrm{xy}}=\mathrm{G}\left(1+\frac{\mathrm{h}}{2 \mathrm{c}}\right) \mathrm{S}_{\mathrm{f}} /\left[2 \mathrm{cG}\left(1+\frac{\mathrm{h}}{2 \mathrm{c}}\right)^{2}-\mathrm{P}_{\mathrm{f}}\right]
$$

As the compressive fiber load approaches the fiber microbuckling load, the shearing stress becomes unbounded. The rate of increase of the shear stress is controlled by the magnitude of the side force. It is assumed, in this case, that the excessive shearing stresses developed may cause the shear failure in a perpendicular direction to the fiber provided that the fiber matrix interface is intact.

The application of the model is the same as the previous model. One needs to find the point where the shearing stress (which is a function of the compressive loads) is compared to the allowable shearing stress at a distance r from the cutout boundary. The allowable stress level is assumed to be the short beam shear strength of the unidirectional material, Table 1. 
The two models are applied to plates with a circular hole. The value of $r$ is determined by using experimental data available in the literature. An analytical approach is used to calculate the stresses around the hole. 


\section{Stress Solution Around a Circular Hole:}

An elasticity solution [12] for the stresses around an elliptical or circular hole is used, in conjunction with classical lamination theory, to determine the location of the point around the hole at which the combination of compressive and shear stress will result in fiber failure for the principal load-carrying lamina. The solution assumes an infinitely large homogeneous anisotropic plane with a traction free elliptical hole. A remote uniaxial stress $\Omega$, at an arbitrary orientation $\alpha$ with respect to the $\mathrm{X}$ axis is applied to the plate, Fig. 4 at infinity. The stress state at infinity is, therefore,

$$
\sigma_{x}^{\infty}=\Omega \cos ^{2} \alpha \quad \sigma_{y}^{\infty}=\Omega \sin ^{2} \alpha \quad \tau_{x y}^{\infty}=\Omega \sin \alpha \cos \alpha
$$

The stress components near the hole for the problem are [12],

$$
\begin{aligned}
& \sigma_{x}=\Omega \cos ^{2} \alpha+2 \operatorname{Re}\left[s_{1}^{2} \phi_{0}^{1}\left(z_{1}\right)+s_{2}^{2} \psi_{0}^{\prime}\left(z_{2}\right)\right] \\
& \sigma_{y}=\Omega \sin ^{2} \alpha+2 \operatorname{Re}\left[\Phi_{0}^{1}\left(z_{1}\right)+\psi_{0}^{\prime}\left(z_{2}\right)\right] \\
& \tau_{x y}=\Omega \sin \alpha \cos \alpha-2 \operatorname{Re}\left[s_{1} \Phi_{0}^{\prime}\left(z_{1}\right)+s_{2} \Psi_{0}^{\prime}\left(z_{2}\right)\right]
\end{aligned}
$$

where the primes denote the derivative of the complex potentials $\Phi_{0}$ and $\Psi_{0}$ with respect to the complex arguments $z_{1}$ and $z_{2}$, respectively, and $s_{1}$ and $s_{2}$ are the non-conjugate roots of a characteristic equation which depends on the anisotropic elastic compliance coefficients. The complex variables $Z_{1}$ and $Z_{2}$ are defined in the cartesian coordinates

$$
z_{1}=x+s_{1} y \quad z_{2}=x+s_{2} y
$$

The derivatives of the complex functions, $\Phi_{0}$ and $\Psi_{0}$ are,

$$
\begin{aligned}
& \vdots_{0}^{1}\left(Z_{1}\right)=A_{1}(\Omega, a) \quad 1-\frac{Z_{1}}{\left(Z_{1}^{2}-\left(a^{2}+s_{1}^{2} b^{2}\right)\right)^{\frac{1}{2}}} \\
& \psi_{0}^{1}\left(Z_{2}\right)=A_{2}(\Omega, a) \quad 1-\frac{Z_{2}}{\left(Z_{2}^{2}-\left(a^{2}+s_{2}^{2} b^{2}\right)\right)^{\frac{1}{2}}}
\end{aligned}
$$




$$
\begin{aligned}
& A_{1}(\Omega, \alpha)=\frac{-i \Omega(a-i s b) b\left(s_{2} \sin 2 \alpha+2 \cos ^{2} \alpha\right)+i a\left(2 s_{2} \sin ^{2} \alpha+\sin 2 \alpha\right)}{4\left(s_{1}-s_{2}\right)\left(a^{2}+s_{1}^{2} b^{2}\right)} \\
& A_{2}(\Omega, \alpha)=\frac{i \Omega\left(a-i s_{2} b\right) b\left(s_{1} \sin 2 \alpha+2 \cos ^{2} \alpha\right)+i a\left(2 s_{1} \sin ^{2} \alpha+\sin 2 \alpha\right)}{4\left(s_{1}-s_{2}\right)\left(a^{2}+s_{2}^{2} b^{2}\right)}
\end{aligned}
$$

For the case of a circular hole under loading along the $y$-axis the two axis, $a$ and $b$, of the ellipse are equal to the hole radius, $R$, and the $\alpha=\pi / 2$. For a plate with finite dimensions, the stresses obtained by the above formulation must be corrected for finite size effects. For orthotropic plates the correction factor is not only a function of the hole aspect ratio, d/W, but also is a function of the degree of orthotropy of the material [16]. In the present work only corrections for finite width from reference [13] are applied. Therefore the examples presented are limited to plates with large length to width ratios. 


\section{Failure Predictions:}

The kinking failure model using both the zero slope end conditions and simply supported end conditions are first used in an effort to capture the essential features of the available experimental data. For comparison predictions are also made by using the point-stress criterion. Experimental data available in the literature is typically for graphite-epoxy specimens. Representative material properties used for graphite-epoxy are given in Table 1.

Experimental-Prediction Correlation: Using the experimental values of the far-field failure strains for quasi-isotropic plates with a hole [2], the value of the distance, $r$, from the crack tip to the failure point is determined to be $1.5 \mathrm{~mm}$ for the kinking model with fixed end conditions and $1.2 \mathrm{~mm}$ for the point stress model, Fig 5 . Since $r$ is assumed to be independent to the laminate layup, this value is used for the rest of the results presented. Predictions are also made for some $\pm 45^{\circ}$-dominated plates with a hole, Fig 5 . The present model agrees well with the experimental results. The point-stress criterion, on the other hand, predicts far field failure strains which are too high for the $\pm 45^{\circ}$-dominated plates and requires a different value of either the distance $r$ or the failure stress as the laminate is changed. This is expected because the failure of $\pm 45^{\circ}$-dominated laminates is affected more by shearing stresses than $0^{\circ}$-dominated laminates, therefore, a model that can include the combined effect of shearing and compressive stresses perform better.

The model that uses the simply supported boundary conditions, on the other hand, did not correlate well with the experimental results, Fig. 6. Therefore, 
in the following discussion only the model with zero slope end conditions is used.

The proposed kinking model was also checked against a recent experimental results [3] to see the effect of the amount of $0^{\circ}$ plies in the laminate on failure loads, Fig 7. Ply orientations for different laminates used are summarized in Table 2. Predictions made by the present and the point-stress models are based on the same $r$ values that are used in Fig 5 . The point-stress model shows increased load carrying capacity as the percent of $0^{\circ}$ plies is increased. The present predictions made for percent of $0^{\circ}$ plies higher than $70 \%$ indicate, however, a drop in the load carrying capacity of the plates. Most of the predictions in the figure are based on the failure of $0^{\circ}$ plies which are principal load-carrying layers in the laminate. But for laminates with a very small thickness of $0^{\circ}$ plies the failure of $0^{\circ}$ plies may not necessarily mean failure of the plate. The solid and dashed lines with dots on them (extended from $0 \% 0^{\circ}$ plies) for small values of the percent of $0^{\circ}$ layers are obtained by assuming the failure to be in the $\pm 45^{\circ}$ plies.

Plates under combined loading: Predictions are also made for plates under the combined action of externally applied compressive and shear loadings. For plates under axial compressive force only, the principal load-carrying plies are the $0^{\circ}$ plies oriented along the loading direction or the plies oriented closest to axial direction. The determination of principal load-carrying plies is less obvious in the case of combined loading. Depending on the ratio of the applied compressive force to the shearing force, $\pm 45^{\circ}$ plies can experience higher compressive stresses than the $0^{\circ}$ plies. In applying the present model or the point-stress model for laminates with different layups, the ply which gives the lowest failure load is assumed to be the one which controls the 
failure. However, we must note that the failure prediction based on the first ply failure is not good when the ply carries a small portion of the applied load. Such cases require further investigation of analytical - experimental failure load correlation to gain confidence in determining plies that are critical for failure. In the present work, for cases where the predictions indicate plies which do not constitute the majority of the thickness are critical, predictions for second most critical plies are also presented.

Failure load predictions, obtained by using the point-stress criterion without the effect of local shearing stresses and the present model, are shown in Fig. 8 for a quasi-isotropic plate with a hole aspect ratio of 0.1 . The failure load is normalized with respect to the failure load of the laminate with no applied shear stress. For small values of the ratio of the shear load to compressive load the present model predicts significant reduction in the load carrying capacity whereas the point-stress criterion predicts negligible effect. For applied shearing stress equal to half the compressive stress, the present model suggests almost $30 \%$ reduction in failure load. Up to this value of the ratio of the shear stress to compressive stress the failure of the plate is governed by the failure of $0^{\circ}$ plies in the laminate. As the relative magnitude of the shear load is increased beyond half the compressive load both models suggest the failure to be driven by the failure of $\pm 45^{\circ}$ plies, and the predictions from both models get closer to each other. For shear stress equal to compressive stress, the reduction in the failure 10 ad is as much as $45 \%$ and both predictions are within $9 \%$ of one another. Similar curves generated by using the present kinking model for different values of hole aspect ratio, Fig. 9, showed a negligible effect of the hole size on failure load ratio. 
Comparison of the failure loads predicted by the present kinking model and the point-stress model are presented in Figs. 10 and 11 for two other laminates, namely laminate $D$ and $F$. The predictions in Fig. 10 for the laminate $D$ are similar to the predictions for the quasi-isotropic laminate in Fig. 8 . The shift of failure from $0^{\circ}$ to $\pm 45^{\circ}$ layers for the two models in Fig. 10, however, occur at two different values of the ratio of the shear load to compressive load and they are both larger than 0.5 obtained for the quasi-isotropic laminate. For the laminate $\mathrm{F}$, both models predict similar reductions in the load carrying capacity if the failure is predicted by the failure of the $\pm 45^{\circ}$ layers in the laminate. However, for small values of the ratio of the shear load to the compressive load the failure is expected to be governed by the failure of the $0^{\circ}$ layers (even to the right of the vertical lines that indicate shift of failure from $0^{\circ}$ to $\pm 45^{\circ}$ plies because $\pm 45^{\circ}$ plies constitute only a small portion of the laminate thickness), and there is a large discrepancy between the predictions of the two models. The predictions based on the $0^{\circ}$ failure are extended beyond the vertical line that indicates shift of failure from 0 to $\pm 45^{\circ}$ plies, and maybe used for failure predictions instead of the ones based on the failure of $\pm 45^{\circ}$ plies.

Normalized failure loads predicted by the present model for four different laminates (including the ones that are discussed above) are summarized in Fig. 12 for a hole aspect ratio of 0.2 . The layup of each laminate is indicated in the figure by letters from Table 2. The laminate with no $0^{\circ}$ plies is the least sensitive one to the presence of the applied shear load. For a ratio of shear to compressive load of 0.5 there is a reduction of only $20 \%$ as opposed to the $\left(0_{48} / \pm 45_{12} / 90_{6}\right)$ laminate $\left(61.5 \% 0^{\circ} \mathrm{plies}\right)$ which the load carrying 
capacity is reduced by $47 \%$. The change in the failure mode $\left(0^{\circ}\right.$ or $\pm 45^{\circ}$ governed failure) is indicated for each line by a short vertical line segment.

\section{Anisotropic plates under compression:}

Failure predictions under pure compressive loads are made for the same set of laminates presented in Table 2 by rotating the principal axis of orthotropy with respect to the loading direction. Because of the anisotropy introduced with respect to the loading axis, applied compressive stresses induce shearing stresses in the plane of the plate. Such configurations proved to be beneficial for advanced aircraft design applications due to improved aeroelastic response [14]. It is expected, however, that such compression shear coupling may result in a more critical stress state around a cutout which would lead to an early failure. Incorporation of the effect of shearing stresses on failure in the present model allows us to asses the effect of an isotropy.

Effect of shear compression coupling on the compressive failure strength is investigated first for a quasi-isotropic plate. Although isotropic in the in-plane stiffness properties, quasi-isotropic laminates demonstrated an anisotropic nature in tensile strength [15]. A reduction observed in strength for off-axis tension specimens is attributed to the interlaminar stresses at the free edge. For the compressive case studied here, change in relative magnitudes of the compressive and shearing stresses around the cutout changed the compressive strength as the laminate is rotated. Ratio of the compressive failure load of a plate with a quasi-isotropic laminate rotated with respect to the loading axis to that of an unrotated plate (loaded along the $0^{\circ} \mathrm{plies}$ ) is given in Fig. 13 for both the present model and point-stress model. The 
point-stress model predicts an increase in the failure load as the angle of rotation approaches $22.5^{\circ}$, whereas, the present model predicts as much as $10 \%$ reduction in the failure load. The difference between the two predictions is entirely due to the inclusion of the shearing stresses around the hole in one of the models.

Similar curves obtained for some of the orthotropic laminates of Table 2 are presented in Figs. 14 through 16 for the range of angle of rotation from 0 to $45^{\circ}$. For the laminate $D$ which is similar to a quasi-isotropic laminate the response, Fig. 14, is similar to the quasi-isotropic layup but the symmetry with respect to the $22.5^{\circ}$ is destroyed. In fact, both models predict decrease in failure load for angle of rotations larger than $35^{\circ}$. For a laminate with a high degree of orthotropy in favor of the applied load direction (laminate F), the failure load decreased significantly as the plate rotated, Fig. 15 . Note that both models predict that the failure to occur at the $\pm 45^{\circ}$ plies (referred to the original layup) when the plate is rotated by $5^{\circ}$. But for such a small percentage of $\pm 45^{\circ}$ plies in the laminate, the final failure may be governed by the failure of $0^{\circ}$ plies. In that case the two models again give contradictory predictions as in the case of quasi-isotropic plates. For a rotation angle of $20^{\circ}$ the present model predicts as much as $25 \%$ reduction in the failure load, whereas point-stress model predicts $10 \%$ increase. For a laminate with a high degree of orthotropy in favor of the direction perpendicular to the loading direction (laminate $\mathrm{C}$ ), on the other hand, the failure load increased as the angle of rotation is increased, Fig. 16. Failure is predicted to be on the $0^{\circ}$. plies for the most part of the range considered for both failure models. Point-stress model predicted significantly higher gains in the failure load compared to the present model. Failure predictions 
by the present model for most of the laminates given in Table 2 are compared in Fig. 17. Largest gains in the failure load is obtained for the laminate B which had mostly $\pm 45^{\circ}$ plies and no $0^{\circ}$ plies. The most serious reductions in the failure load is obtained for the laminate with mostly $0^{\circ}$ plies.

Anisotropic plate configurations mentioned above is assumed to deform freely under the compressive loads. Because of the shear compression coupling introduced by the anisotropy with respect to the loading axis, the plate deforms in shear and the loaded edge shifts sideways. If one tests such an anisotropic configuration, on the other hand, the in-plane shear deformation would, most probably, be prevented by the support fixture at the loaded edge. This is equivalent to applying a shear load in a direction opposite to the rotation of the plate as the compressive load is applied. Failure predictions simulating such a combined loading for anisotropic plates are given in Fig. 18 for the laminate F. For simplicity the magnitude of the shearing force is assumed to be equal to half of the applied compressive load. In an actual case the ratio of the shear load to the compressive load would be a function of angle of rotation of the principal axis of orthotropy with respect to the loading direction. The failure load in the figure is normalized with respect to the failure load of unrotated plate without the applied shear load. Comparing the failure loads in Figs. 18 and 15 for angle of orientation of $20^{\circ}$, for example, reveals that if the shear load was equal to half of the compressive load at that configuration the failure load of the plate restrained against shear deformation would be larger than the unrestrained plate at the same configuration. Fig. 18 also demonstrates the fact that if the applied loading is a combined compression and shear, the best result may be achieved by orienting the principal axis of orthotropy to oppose the shearing load. 
Concluding Remarks:

Failure models for the prediction of compressive strength of plates with a hole are investigated. One of the models, previously developed and applied for plates with a crack, is based on the strength failure of the fibers that leads to fiber kinking failure. A different version of the model is also developed for cases where shear failure of the fibers are expected to be a dominant failure mode. Both models are capable of including the effects of combined shearing and compressive stresses around a hole in a plate and, therefore, are expected to be applicable to plates under combined shearing and compressive loadings and anisotropic plates. Comparison of the predictions of both models with the available experimental results for quasi-isotropic and orthotropic plates indicated a good agreement for the kinking failure model. Because of the relatively poor agreement of the shear failure model with experimental results compared to the kinking model, predictions are made for anisotropic plates under combined loadings only with the kinking model. Further investigation of the shear failure model may be justified for plates under pure shearing loads which is not included in the present work.

Predictions for orthotropic plates under combined shearing and compressive loadings are made by using the fiber kinking and the point-stress models. While the point-stress model predicted moderate decrease in load carrying capacity of the plate compared to the plate loaded only in compression, the fiber kinking model indicated significant reductions for cases where $0^{\circ}$ plies are critical. When $\pm 45^{\circ}$ plies are expected to dominate the failure, both models displayed similar predictions .

Predictions are also made for anisotropic plates obtained by rotating the principal axis of orthotropy of an orthotropic plate with respect to the 
loading axis by using both kinking and point-stress failure models. When the failure is predicted with the failure of $0^{\circ}$ plies the two models gave contradictory results. For example, for a quasi-isotropic plate the kinking model predicted strength reductions whereas point-stress model predicted increase in strength. For an anisotropic plate under combined shearing and compressive loads (shearing load applied in a direction opposite to the side deflection of the plate) the failure load predictions were larger than the failure load of the same plate under same loading but loaded orthotropically (i.e. loaded along the principal axis of orthotropy). 


\section{References}

[1] Nuismer, R. J., and Labor, J. D., "Application of the Average Stress Failure Criterion: Part II-Compression," Journal of Composite Materials, Vo1. 13, pp. 49-60, January 1979.

[2] Rhodes, M. D., Mikulas M. M. Jr., and McGowan, P. E., "Effects of Orthotropy and Width on the Compression Strength of Graphite-Epoxy Panels with Holes." AIAA Journa1, Vo1. 22, No. 9, 1984, pp. 1283-1292.

[3] Haftka, R. T., and Starnes, J. H., Jr., "Use of Optimum Stiffness Tailoring to Improve the Compressive Strength of Composite Plates with Holes," Presented at the AIAA/ASME/ASCE/AHS 26th Structures, Structural Dynamics, and Materials Conference, Orlando, Florida, April 1985.

[4] Rosen, B. W., "Mechanics of Composite Strengthening," Fiber Composite Materials, American Society of Metals, Metals Park, Ohio, October 1964.

[5] Greszczuk, L. B., "Microbuckling of Lamina-Reinforced Composites," Composite Materials: Testing and Design (Third Conference), ASTM STP 546, American Society for Testing and Materials, 1974, pp. 5-29.

[6] Hahn, H. T., and Williams, J. G., , "Compression Failure Mechanisms in Unidirectional Composites," NASA Technical Memorandum 85834, National Aeronautics and Space Administration, Langley Research Center, Hampton, Virginia 23665, August 1984.

[7] Evans, A. G., and Adler, W. F., "Kinking as a Mode of Structural Degradation in Carbon Fiber Composites," Acta Metallurgica, Vol. 26, pp. $725-738,1978$.

[8] Berg, C. A., and Salama, M., "Fatigue of Graphite Fiber-reinforced Epoxy in Compression," Fiber Science and Technology, Vol. 6, p. 79, 1973.

[9] Parry, T. V., and Wronski, A. S., "Kinking and Compressive Failure in Uniaxially Aligned Carbon Fibre Composite Tested Under Superposed Hydrostatic Pressure," Journal of Materials Science, Vo1. 17, pp. $893-900,1982$.

[10] Weaver, C. W., and Williams, J. G., "Deformation of a Carbon-epoxy Composite under Hydrostatic Pressure," Journal of Materials Science, No. 10, pp. 1323-1333, 1975.

[11] Gürdal, Z., "Automated Design of Composite Plates for Improved Damage Tolerance," Ph.D. Dissertation, Virginia Polytechnic Institute and State University, Blacksburg, VA 24061, January 1985.

[12] Savin, G. N., "Stress Concentrations around Holes," Pergamon press, Oxford, 1961. 
[13] Hong, C. S., and Crews, J. H., "Stress Concentration Factors for Finite Orthotropic Laminates with a Circular Hole and Uniaxial Loading," NASA Technical Paper 1469, NASA Scientific and Technical Information Office, 1979 .

[14] Lynch, R. W., and Rogers, W. A., "Aeroelastic Tailoring of Composite Materials to Improve Performance," Proceedings of the AIAA/ASME/SAE, 17th Structures, Structural Dynamics, and Materials Conference, King of Prussia, Pennsylvania, May 5-7, 1976.

[15] Zhou, S. G., and Sun, C. T., "Strength of Quasi-isotropic Composite Laminates Under Off-axis Loading," Proceedings of the AIAA/ASME/ASCE/AHS 27 th Structures, Structural Dynamics, and Materials Conference, Orlando, Florida, 1985 . 
Table 1: Unidirectional material properties used.

$\begin{array}{lr}\text { Longitudinal Modulus, GPa } & 131.0 \\ \text { Transverse Modulus, GPa } & 13.0 \\ \text { Shear Modulus, GPa } & 6.4 \\ \text { Major Poisson's Ratio } & 0.38 \\ \text { Thickness, mm/ply } & 0.14 \\ \text { Fiber Volume Fraction } & 0.71 \\ \text { Short Beam Shear Strength, MPa } & 131.0 \\ \text { Fiber Compressive Strength, GPa } & 2.4 \\ \text { Fiber Thickness, mm } & 0.008 \\ \text { Critical Fiber Length, mm } & 0.05\end{array}$

Table 2: Ply orientation and thickness of various laminates used for failure predictions.

\begin{tabular}{|c|c|c|c|}
\hline Laminate & Ply orientation & Thickness, mm. & $0^{\circ}$ plies, $\%$ \\
\hline A & $0_{12} / \pm 45{ }_{12} / 90{ }_{12}$ & 6.72 & 25.0 \\
\hline B & $45_{36} / 906$ & 10.92 & - \\
\hline $\mathrm{C}$ & $0_{12} / \pm 45_{30} / 90_{6}$ & 10.92 & 15.4 \\
\hline $\mathrm{D}$ & $0_{24} / \pm 4524^{190}$ & 10.92 & 30.8 \\
\hline E & $0_{36} / \pm 45{ }_{18} / 90_{6}$ & 10.92 & 46.2 \\
\hline $\mathbf{F}$ & $0_{48} / \pm 45_{12} /{ }^{90} 6$ & 10.92 & 61.5 \\
\hline G & ${ }_{60} / \pm 45{ }_{6} / 906$ & 10.92 & 76.9 \\
\hline
\end{tabular}


ORIGITAL PAGE IS

OF POC: $\mathrm{n}^{-\cdots}$

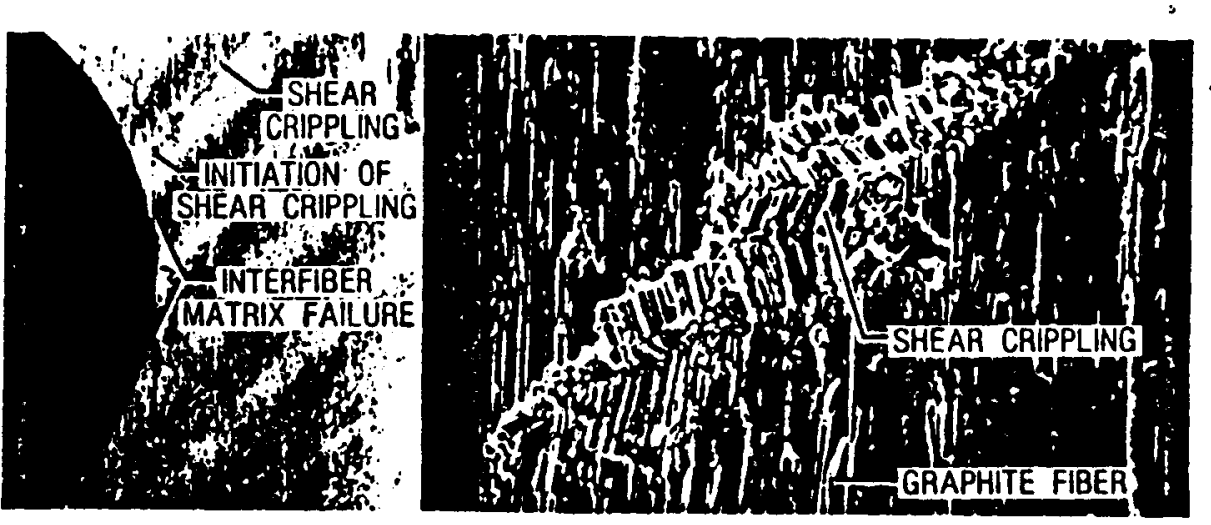

Figure 1: Shear crippling failure of a specimen with a hole, from reference 2 .

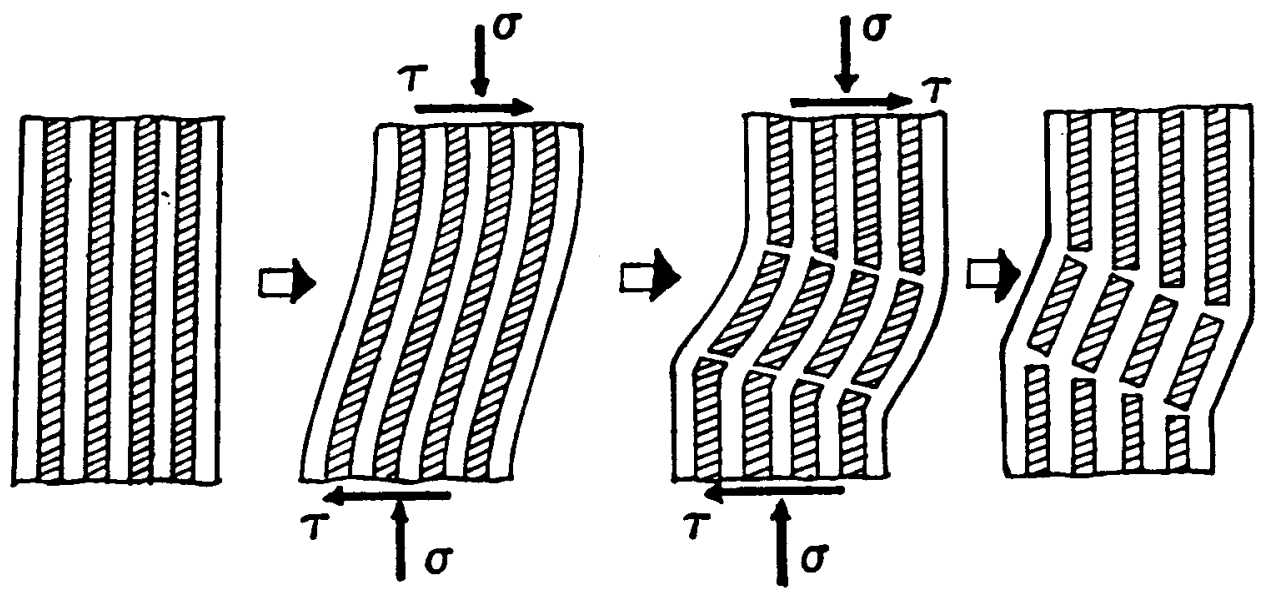

Figure 2: Kinking mode of compressive failure. 

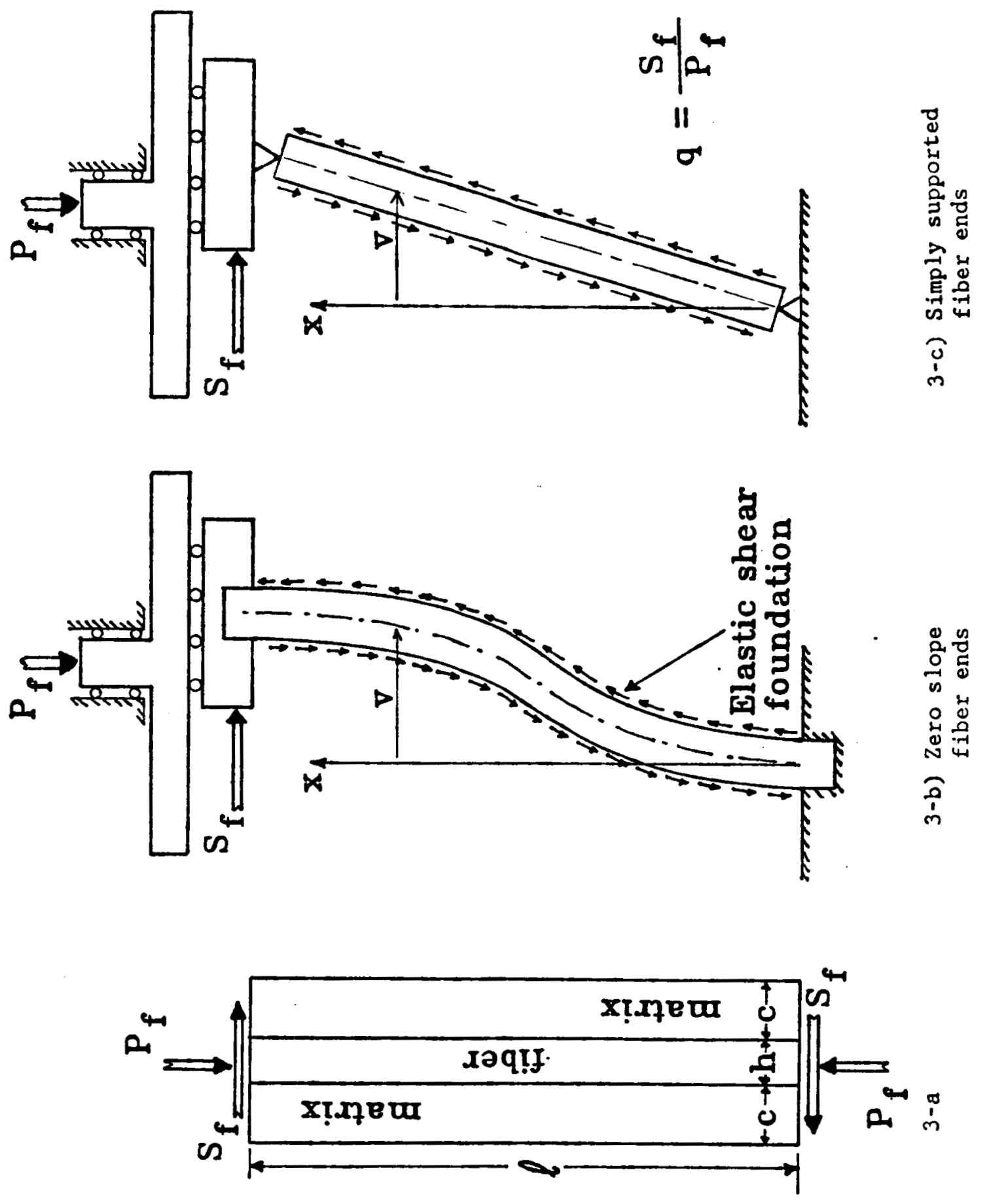


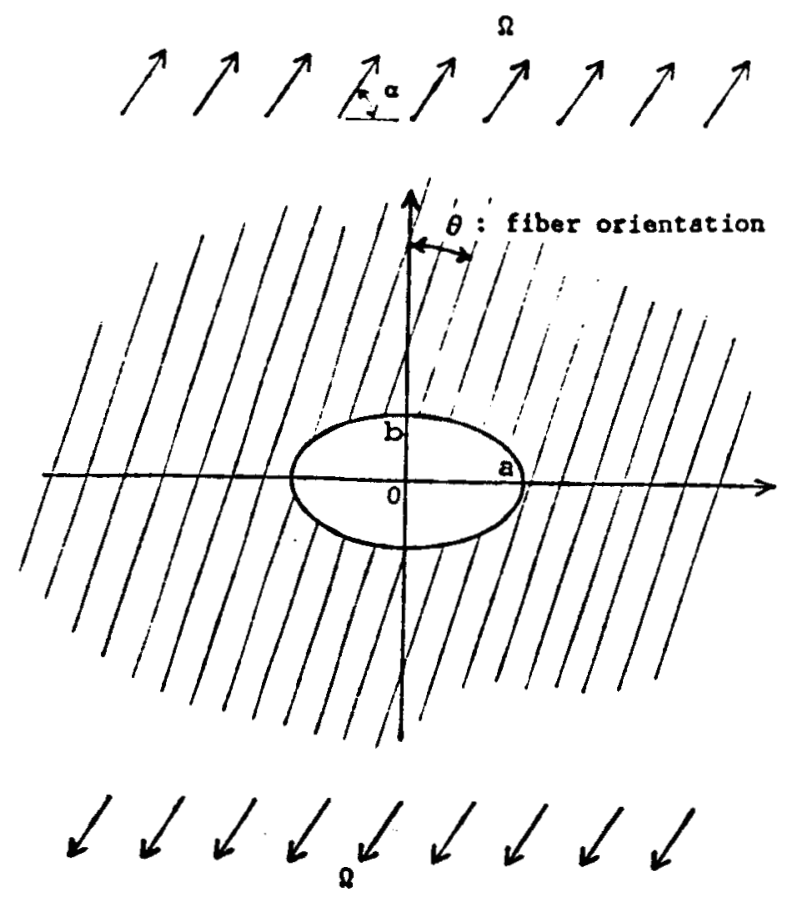

Figure 4: Infinite plate with an elliptical cutout.

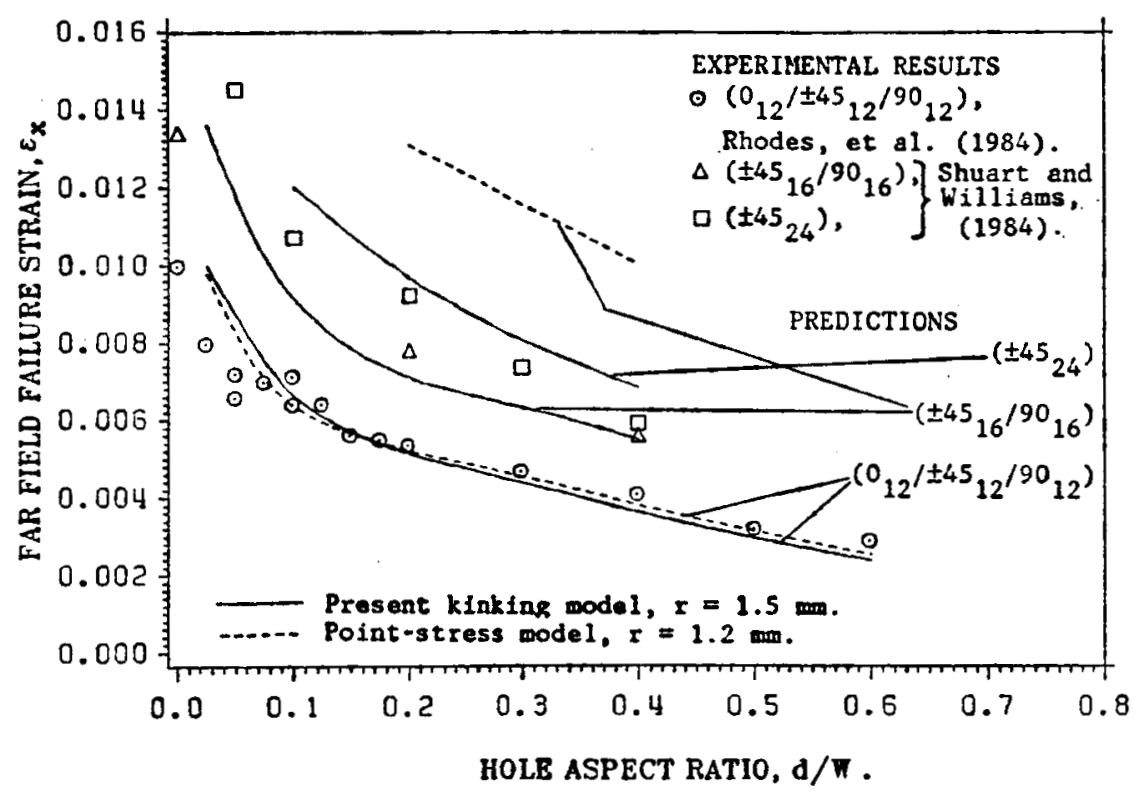

Figure 5: Compressive failure of plates with a hole. 


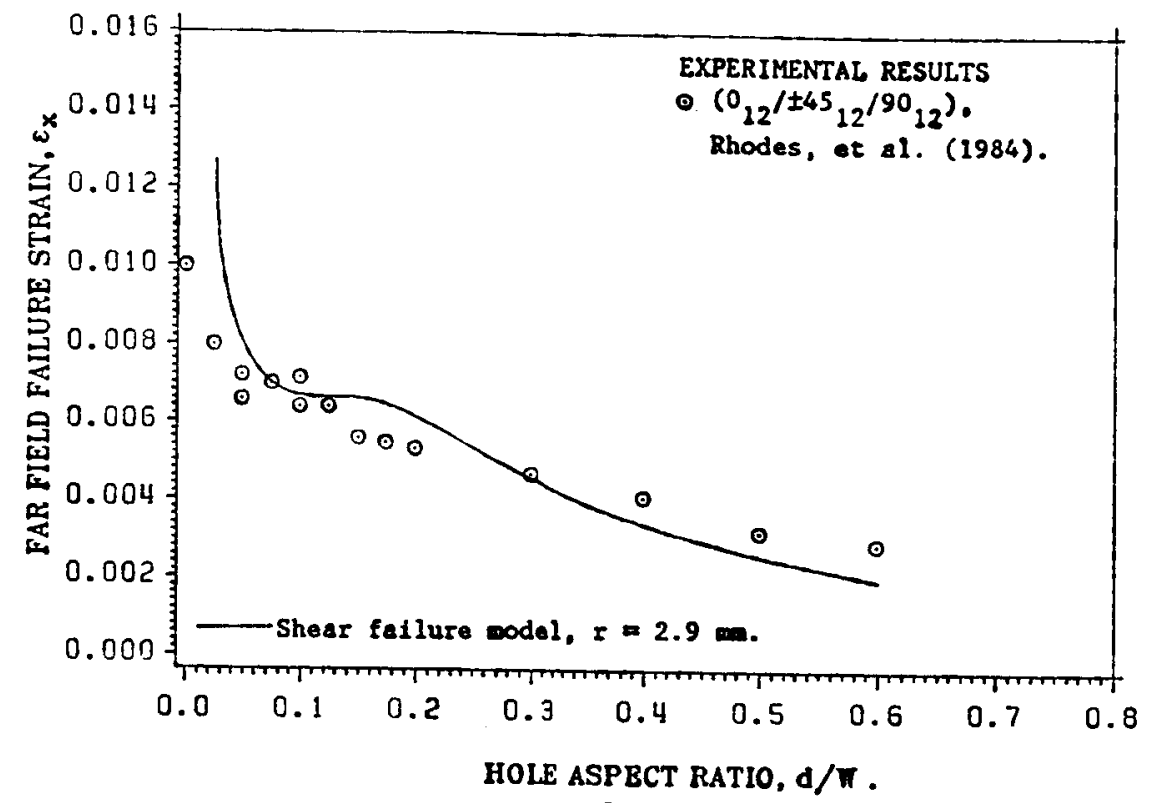

Figure 6: Compressive failure of quasi-isotropic plates with a hole.

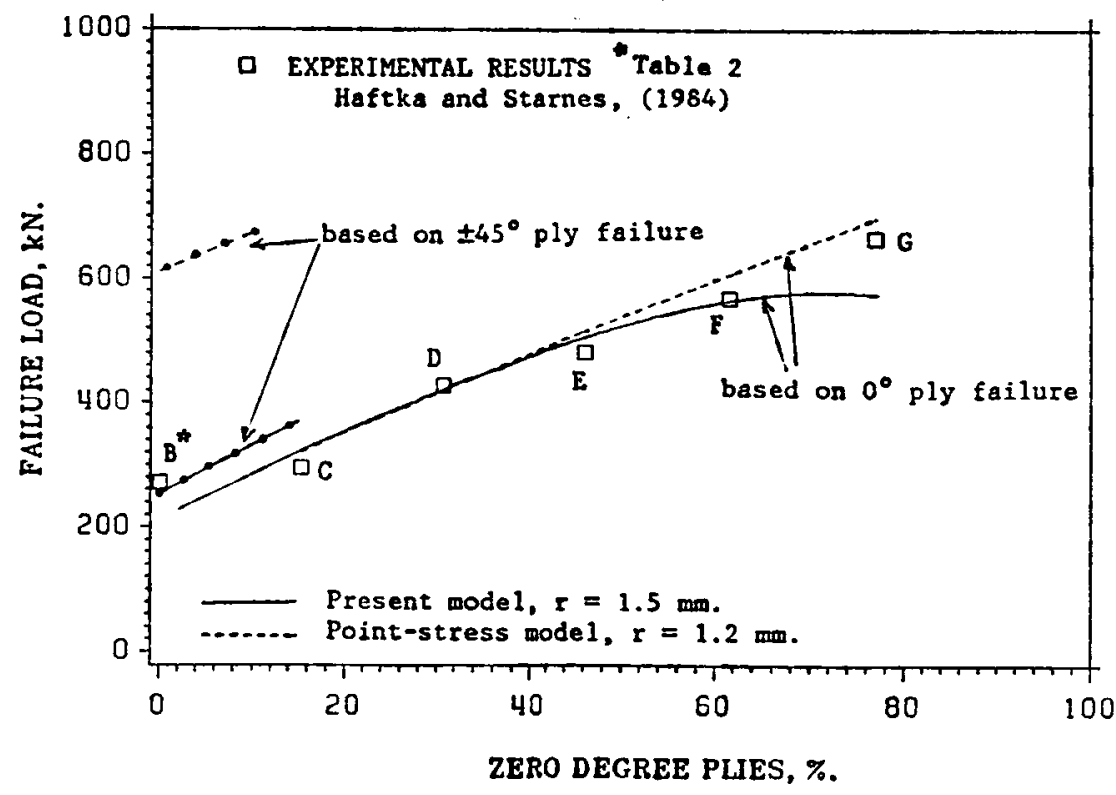

Figure 7: Compressive failure of plates with different layups. 


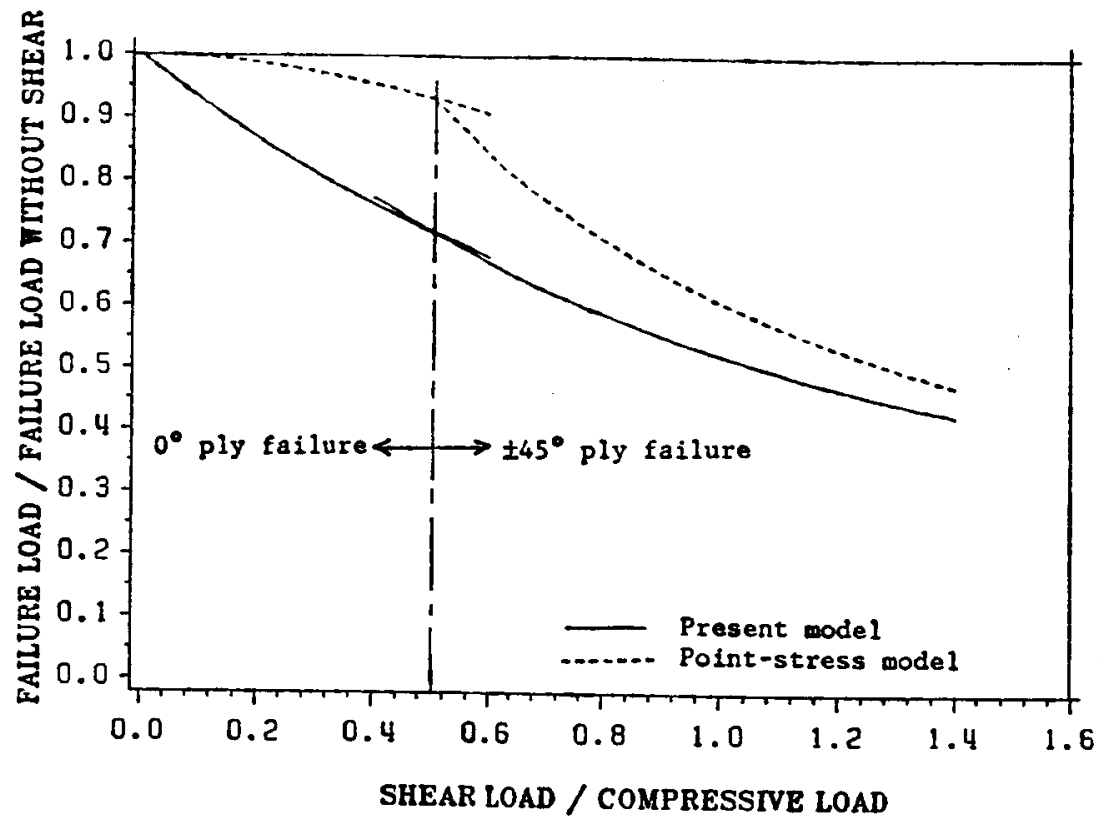

Figure 8: Effect of shear load on a quasi-isotropic plate.

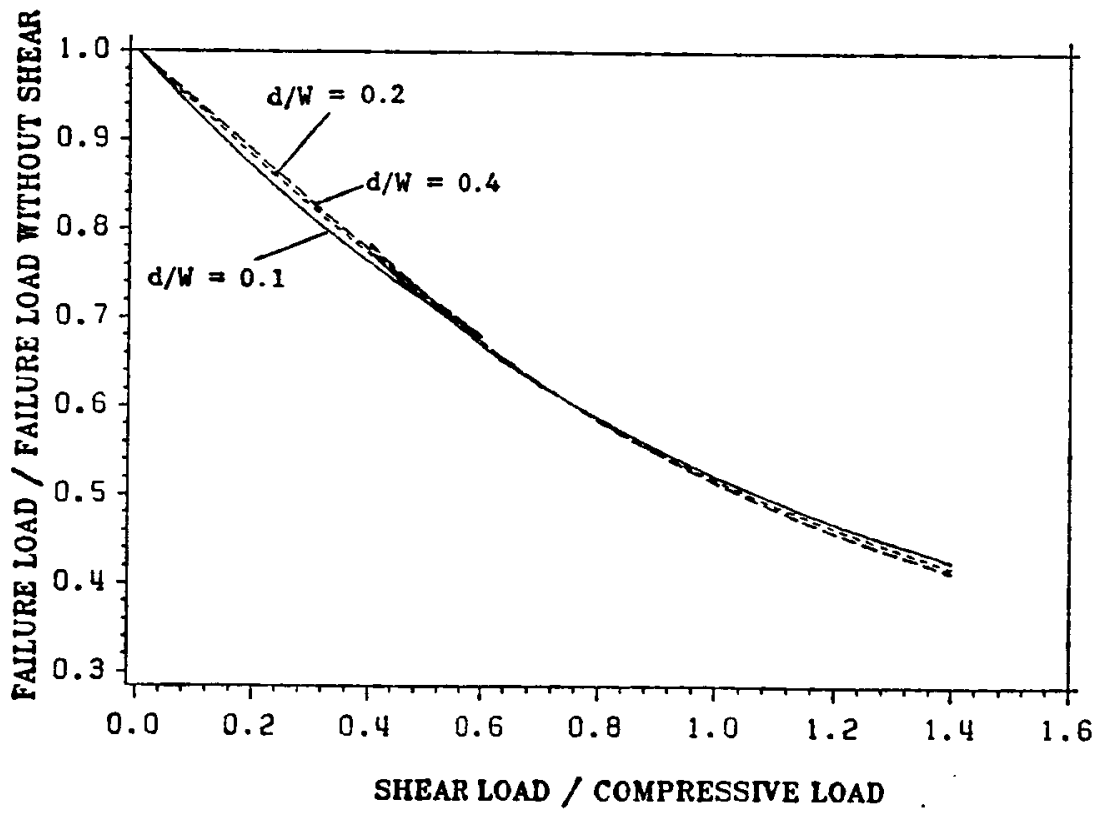

Figure 9: Effect of hole size on quasi-isotropic plates under combined compression and shear. 


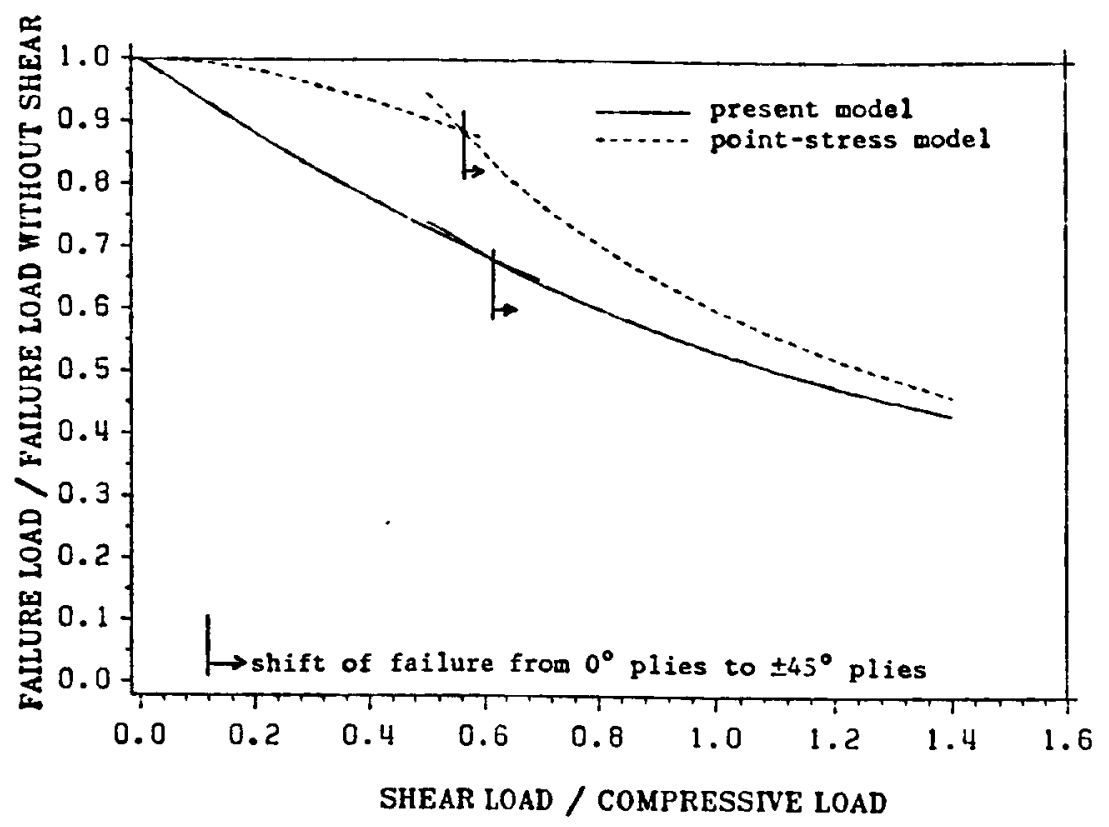

Figure 10: Effect of shear load on laminate D, Table 2.

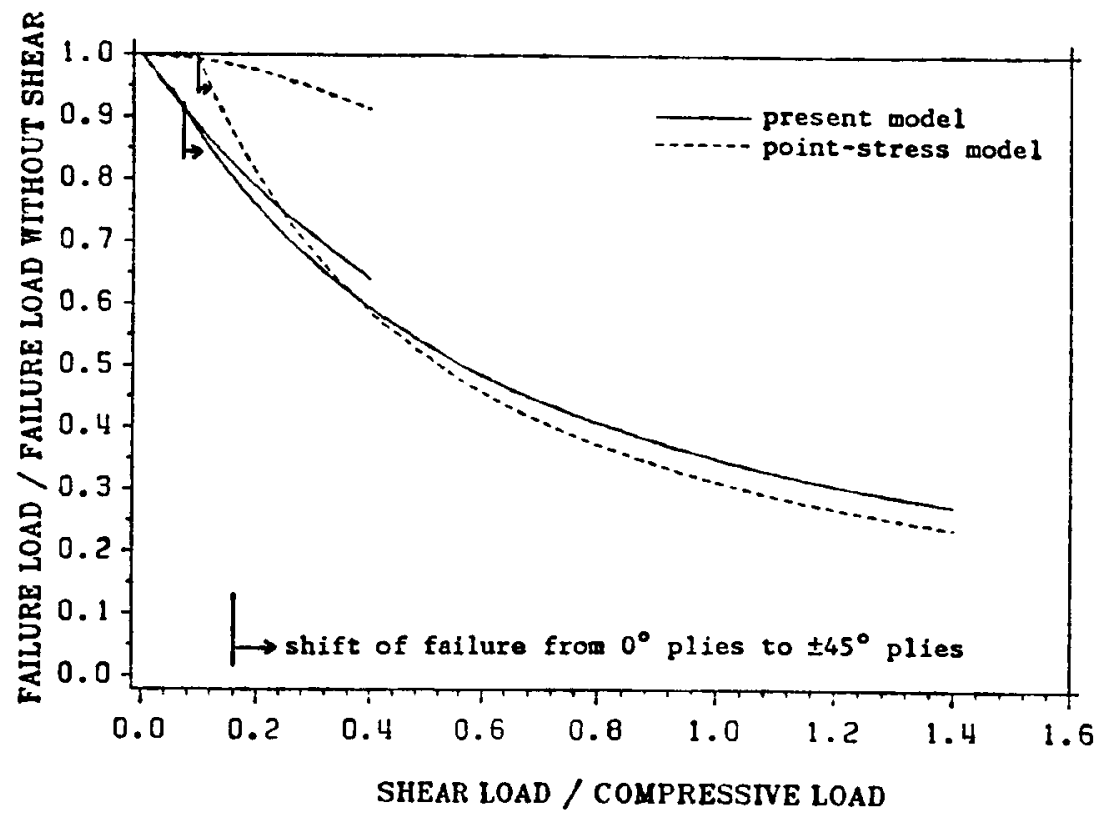

Figure 11: Effect of shear load on laminate $F$, Table 2. 


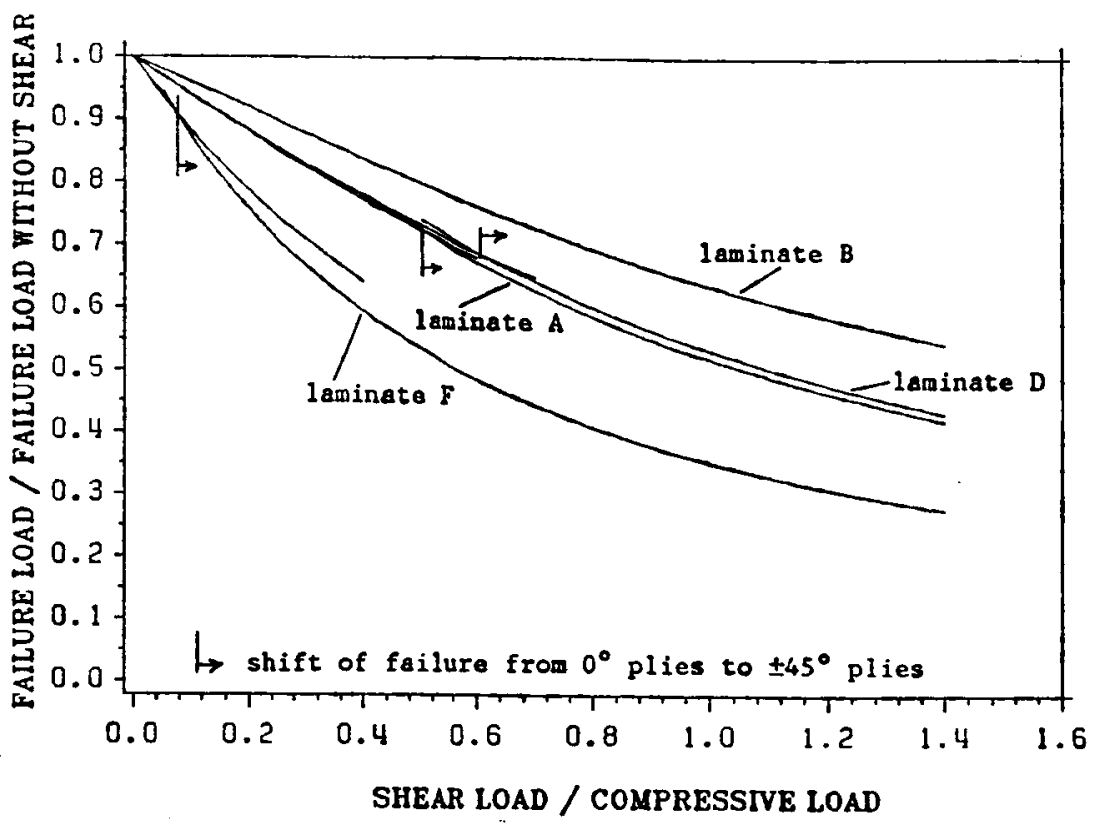

Figure 12: Effect of shear load on plates with different layups.

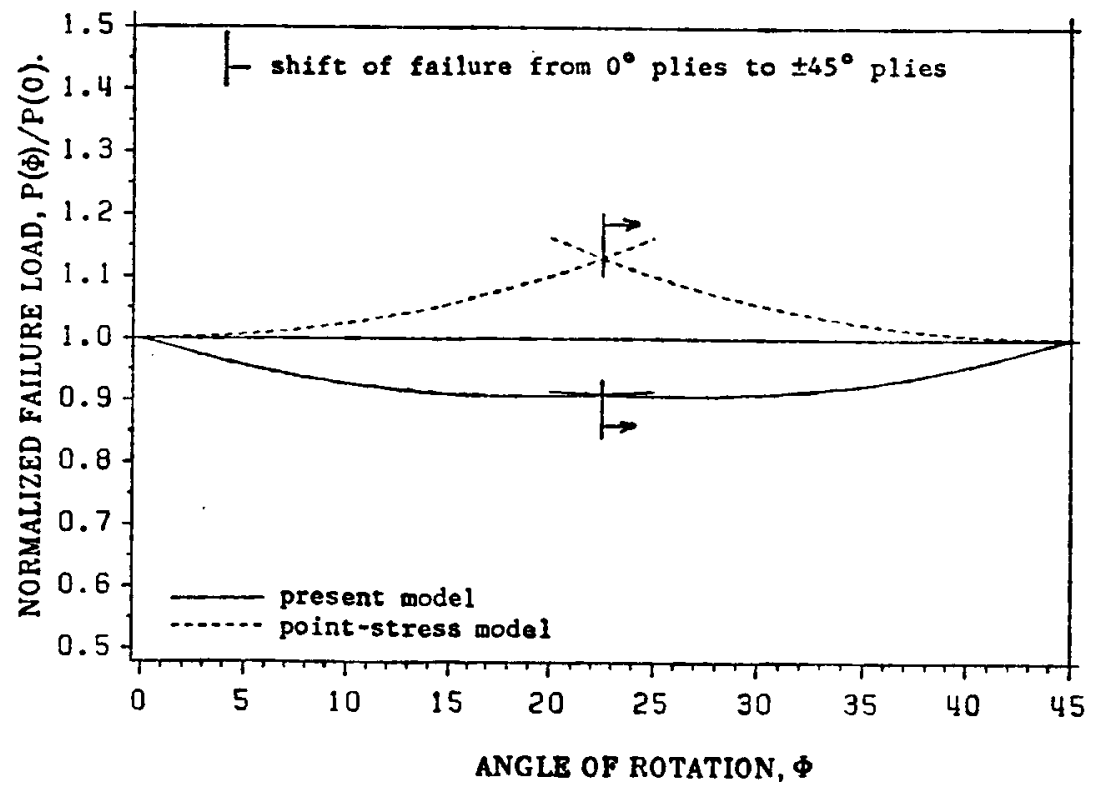

Figure 13: Compressive strength of a plate with a quasi-isotropic laminate rotated with respect to the loading axis. 


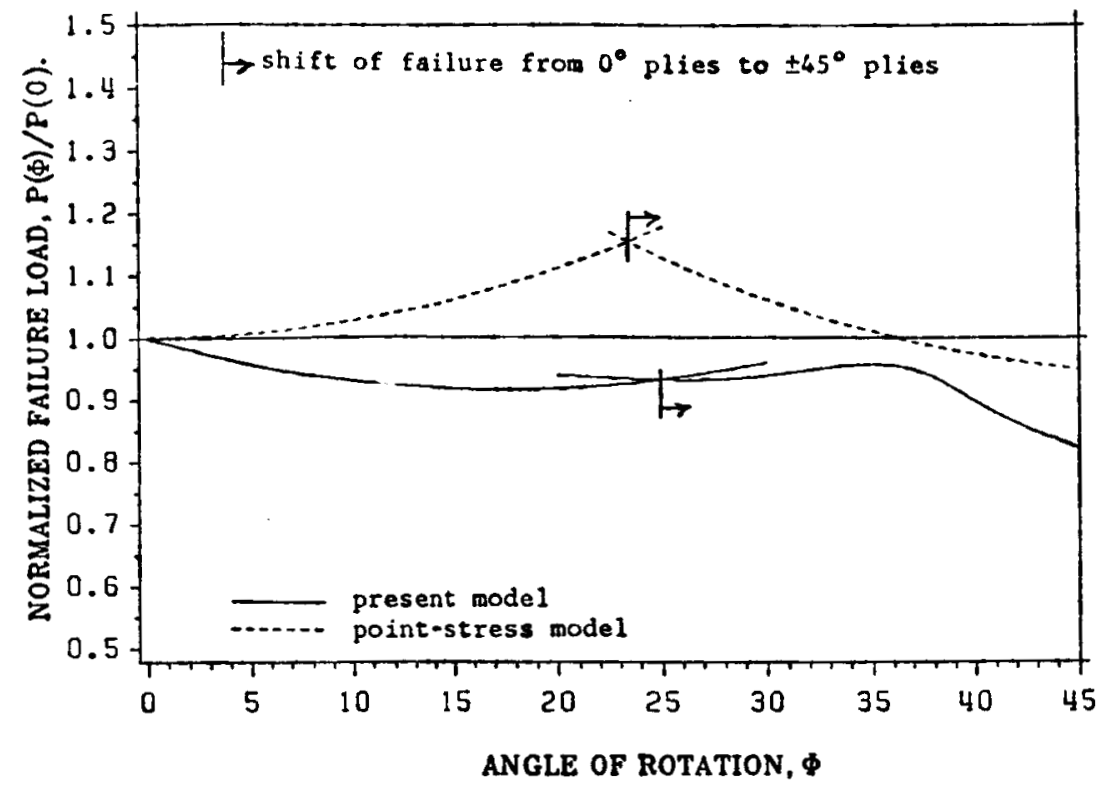

Figure 14: Compressive strength of a plate with an orthotropic laminate (laminate $D$, Table 2 ) rotated with respect to the loading axis.

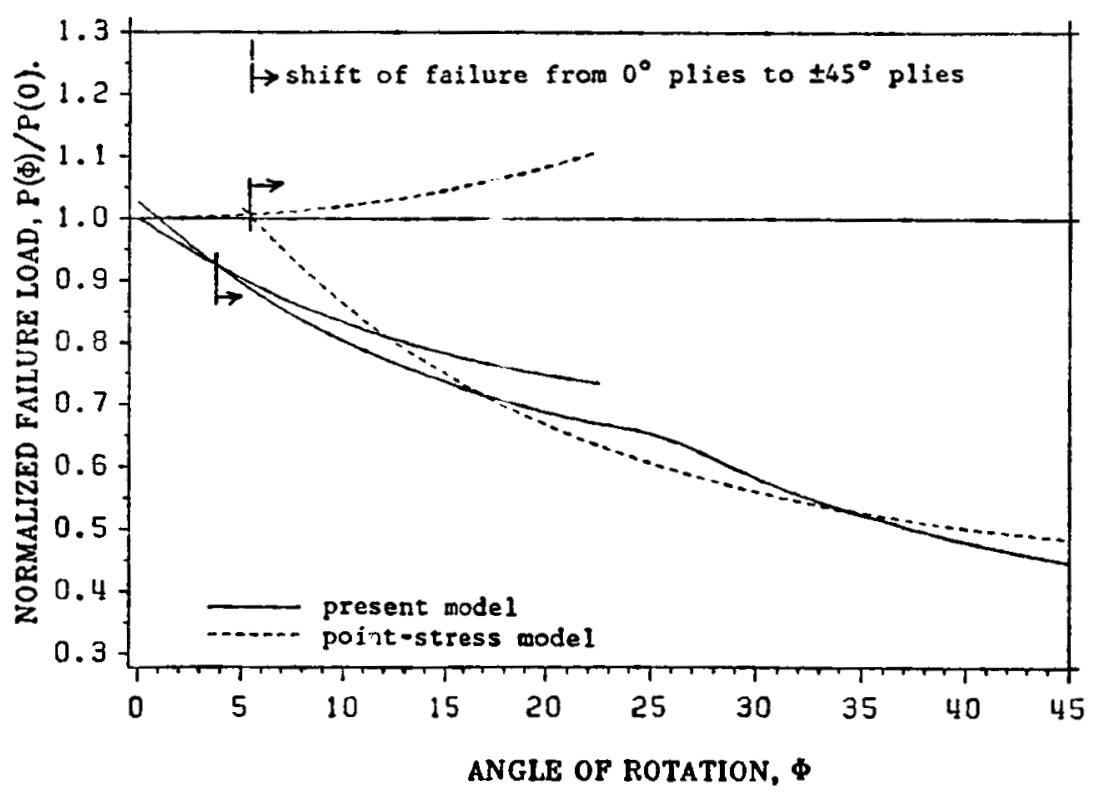

Figure 15: Compressive strength of a plate with an orthotropic laminate (laminate $F$, Table 2 ) rotated with respect to the loading axis. 


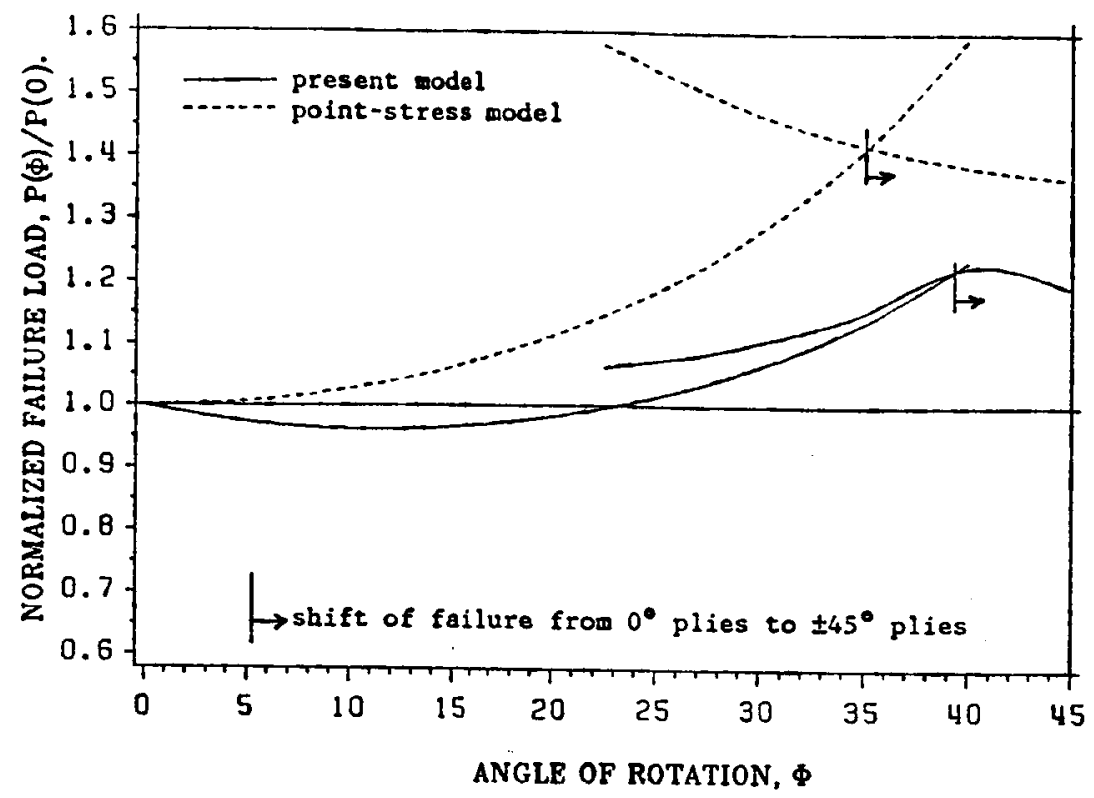

Figure 16: Compressive strength of a plate with an orthotropic laminate (laminate $C$, Table 2 ) rotated with respect to the loading axis.

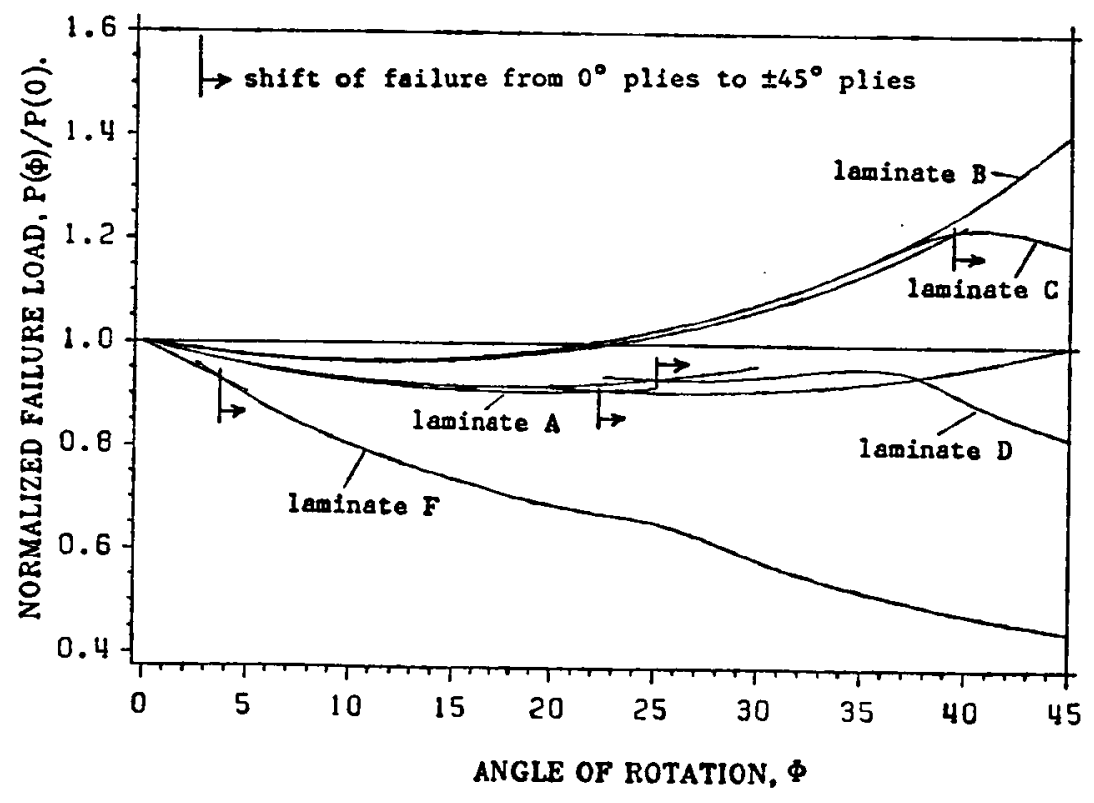

Figure 17: Comparison of compressive strength of plates different laminates rotated with respect to the loading axis. 


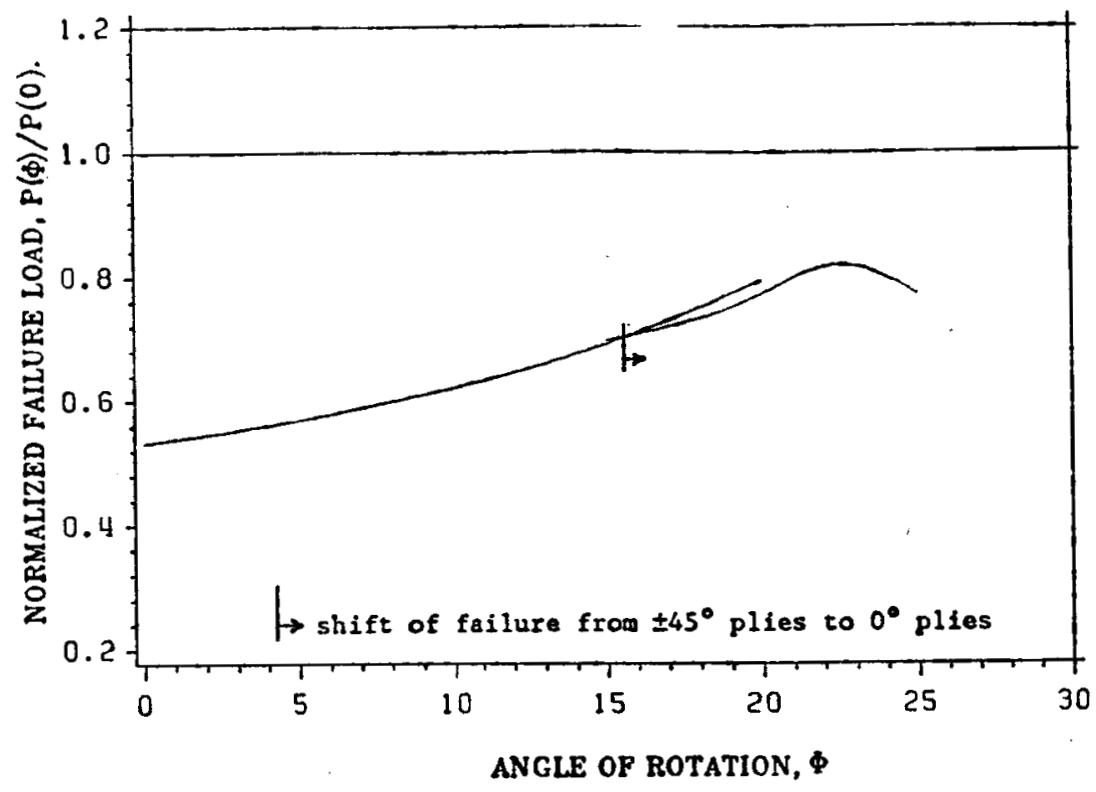

Figure 18: Compressive strength of a plate with laminate $F$ rotated with respect to the loading axis under combined compressive and shear loading (shear. loading $50 \%$ of the compression). Failure load is normalized with respect to the unrotated plate without shear. 